\title{
The Economic Impact of Payments for Water-related Ecosystem Services on Protected Areas: A Synthetic Control Analysis
}

\section{Jianmei Zhang ( $\sim 419190787 @ q q . c o m$ )}

Xi'an University of Technology https://orcid.org/0000-0001-8514-5994

Jiwei Zhu

Xi'an University of Technology

Yu Liu

Xi'an University of Technology

Nan Lu

Xi'an University of Technology

\section{Wenxing Fang}

Xi'an University of Technology

\section{Research Article}

Keywords: Payments for water-related ecosystem services, Synthetic control method, Economic growth, Headwater areas of the South to North Water Diversion Project

Posted Date: December 28th, 2021

DOI: https://doi.org/10.21203/rs.3.rs-1196626/v1

License: (c) (i) This work is licensed under a Creative Commons Attribution 4.0 International License.

Read Full License

Version of Record: A version of this preprint was published at Water Resources Management on March 14th, 2022. See the published version at https://doi.org/10.1007/s11269-022-03099-z. 


\section{Abstract}

Payments for water-related ecosystem services (PWES) are increasingly popular in promoting water ecological conservation, and their impacts on development are of considerable interest. This study estimates the economic impact of PWES on protected areas by applying the synthetic control method. Using the Middle Route of the South to North Water Diversion Project in China as a case study, we find that per capita GDP in protected areas increased markedly relative to a synthetic control region, and PWES has a positive economic impact. In addition, we conduct a variety of placebo tests to verify the validity and robustness of the results. We believe that the main factor of the positive economic impact lies in the development of the ecological-economic industrial system. This study provides a baseline for synthetic control analysis of PWES to compare regions of interest and their counterfactuals, and the findings of the case study provide reference to the protected areas for their economic development.

\section{Introduction}

Water ecosystems provide a wide range of environmental services that contribute to human well-being, such as water supply, water purification, and biodiversity maintenance (Kaplowitz et al. 2012). However, with the rapid development of the economy and society, achieving a sustainable balance between human and ecological need for water is becoming a substantial challenge (Akhbari and Grigg 2013; Boelee et al. 2017). Payments for water-related ecosystem services (PWES), a branch of payments for ecosystem services (PES), is a market mechanism that service buyers use to pay service providers (Engel et al. 2008; Pacetti et al. 2020). The PWES is increasingly being used in many national ecological projects as an effective tool for maintaining the balance between ecological environment protection and water services utilization(de Groot and Hermans 2009; Huber-Stearns et al. 2015; Piaggio and Siikamäki 2021; Shang et al. 2018; Wunder and Albán 2008).

As the largest water diversion project in the world, the South to North Water Diversion Project (SNWD) in China aims to provide water resources to important regions such as Beijing, Tianjin, Hebei, and Henan to alleviate the pressure of water scarcity (Zhao et al. 2017). To provide quality water, cities in the headwater areas, that is, ecosystem service providers, have protected water through restoration and conservation measures and reduced water pollution by limiting the development of highly polluting industries. Thus, through the PWES policy, the central government and local governments in water-receiving areas pay headwater cities for their protection and development losses (Li et al. 2021).

The PWES policy has impacts on protected areas in various aspects (Locatelli et al. 2008). The existing literature on the impact of this policy focuses on three key questions: (1) the impact on socio-economy, mainly regarding changes in the income, consumption, and employment of the service providers, and the resulting effect on households and poverty alleviation (Hegde and Bull 2011; Liu and Kontoleon 2018; Miranda et al. 2003); (2) the impact on culture and institutions, which indicates that PWES can raise environmental awareness and improve institutional processes (Alix-Garcia et al. 2018; Torres 2016; Van Hecken et al. 2015); and (3) the impact on the ecological environment, which shows that PWES results in 
the accumulation of carbon sequestration, reduction of soil erosion, and improvement of aquatic ecosystems (Azevedo de Melo et al. 2021; MEA 2005). However, the economic impacts of PWES on protected areas at the aggregate level are not clearly distinguished from the business-as-usual course. Many people intuitively think that economic development may be held back by the closure of some industrial enterprises for environmental purposes (Zhang et al. 2020). For large-scale projects as the SNWD, there is still no thorough study on whether the PWES policy hinders or facilitates the economic growth of protected areas.

Many approaches can be used to evaluate the impact of a certain policy on a certain region in socioeconomics (Angrist and Pischke 2017), among which the synthetic control method is relatively new. Because of its attractive features of transparency in choosing synthetic control units and safeguarding against extrapolation (Abadie et al. 2011), the synthetic control method has been increasingly applied to the evaluation of policy effects (Ando 2015; Grier and Maynard 2016; Peng et al. 2020). Thus, we use the synthetic control method to study the economic impact of PWES.

In line with the strategic significance of the national economy, as well as the practical approaches of major projects, we use the Middle Route of the SNWD as a case study to investigate the economic impact of PWES on protected areas. The novelty of this study lies in that it is a systematic and groundbreaking study on the aggregate economic impact of headwater cities, and the synthetic control method is pioneered in the field of PWES, which provides technical support for impact estimation.

\section{Methods And Case Description \\ 2.1 Methods}

We regard the intervention of the PWES scheme as a policy experiment carried out by the government in protected areas. Let $Y_{i t}$ be the outcome of economic growth for region i at time t; thus, $Y_{i t}(1)$ and $Y_{i t}(0)$ represent the outcome variables with and without intervention, respectively. Concerning Abadie et al. (2010, 2015), $Y_{i t}(1)$ and $Y_{i t}(0)$ can be

$$
\begin{aligned}
& Y_{i t}(0)=\delta_{t}+\boldsymbol{\theta}_{t} \boldsymbol{Z}_{i}+\boldsymbol{\lambda}_{t} \boldsymbol{\mu}_{i}+\varepsilon_{i t} \\
& Y_{i t}(1)=Y_{i t}(0)+\tau_{i t} D_{i t}
\end{aligned}
$$

2

where $\mathrm{Zi}$, also known as a predictive variable, is a set of factors that influence economic growth, $\delta \mathrm{t}$ represents a time fixed effect, $\lambda$ t represents a common shock, $\mu i$ is an individual fixed effect, $\varepsilon$ it represents random shocks. Dit is a dummy variable that indicates whether region $\mathrm{i}$ is exposed to the policy. For the treatment region $\mathrm{i}=\mathrm{J}+1$, when $\mathrm{T} \geq \mathrm{T} 0$ (the timing of intervention), Dit is 1 , while the rest are 0 . 
$Y_{i t}(0)$ of the treatment region $(i=J+1)$ can be approximated by the weighted average of $Y_{i t}(1)$ of the control regions $(i \in\{1, \ldots, J\})$, which can be observed. Define as a $(J \times 1)$ vector of weights $W=$ $(\omega 1, \ldots, \omega j)^{\prime}, \omega_{i}$ represents the relative contribution of each control unit to the synthetic region. For any $\omega_{1} \in W, 0 \leq \omega_{i} \leq 1$, and $\omega_{1}+\omega_{2} \ldots+\omega_{J}=1$. The synthetic outcome is

$$
\sum_{i=1}^{J} \omega_{i} Y_{i t}=\delta_{t}+\theta_{t} \sum_{i=1}^{J} \omega_{i} Z_{i}+\lambda_{t} \sum_{i=1}^{J} \omega_{i} \mu_{i}+\sum_{i=1}^{J} \omega_{i} \epsilon_{i t}
$$

3

The unbiased estimate of the economic effect after the intervention is

$$
\hat{\tau_{\mathrm{J}+1, \mathrm{t}}}=Y_{J+1, t}(1)-Y_{J+1, t}(0)=Y_{J+1, t}(1)-\sum_{i=1}^{J} \omega_{i}^{*} Y_{i t}, t \in\left\{T_{0}, \ldots T\right\}
$$

4

To choose the optimal $\mathrm{W}^{*}$, let $X_{1}$ be a $(k \times 1)$ vector of preintervention predictors for the treatment region and $X_{0}$ be a $(k \times J)$ matrix of the corresponding predictors of the potential control regions. We hope $X_{0} W^{*}$ could best approximate $X_{1}$, so $W^{*}$ minimizes

$$
\min _{W} \sqrt{\left(X_{1}-X_{0} W\right)^{\prime} V\left(X_{1}-X_{0} W\right)}
$$

5

where $V$ is some $(k \times k)$ symmetry, with the non-negative diagonal element representing the contribution of each predictor to the outcome.

Furthermore, we select the optimal $V^{*}$ such that during the preintervention period, $Z_{1}$, the outcome of the treated region is best resembled by $Z_{0}$, corresponding to the outcome of the synthetic region. Therefore, $V^{*}$ minimizes the mean square prediction error (MSPE).

$$
\mathrm{V}^{*}=\arg \min _{V} \frac{1}{T_{p}}\left(Z_{1}-Z_{0} W^{*}(V)\right)^{\prime}\left(Z_{1}-Z_{0} W^{*}(V)\right)
$$


The nested optimization problem that minimizes equation (6) can be solved for $W^{*}(V)$ given by Equation

(5). By substituting $W^{*}(V)$ into equation (4), we can estimate the value of the economic effect $\tau_{\mathrm{J}+1, \mathrm{t}}$ for the post-treatment period.

\subsection{Case description 2.2.1 Study Area}

The Middle Route of the South-to-North Water Diversion Project (SNWD-MR) discharges water from the Danjiangkou Reservoir in the upper and middle reaches of the Hanjiang River (Zhao et al. 2017). The headwater areas are distributed in Shaanxi, Hubei, Henan, Gansu, Sichuan provinces, and Chongqing municipality, involving 11 cities or 49 counties (see Figure 1). Among the cities involved, Hanzhong, Ankang, and Shangluo in Shaanxi, as the origin of the Hanjiang and Danjiang rivers, account for $70 \%$ of the annual water inflow to the Danjiangkou Reservoir, which plays a prominent role in ensuring the water quality in SNWD-MR (NDRC et al. 2017).

To protect water resources, the three cities of Hanzhong, Ankang, and Shangluo have continuously adjusted their economic structure and development mode, controlled pollutant emissions, and shut down enterprises and mineral operations with serious pollution, which has a huge impact on economic development. To compensate for the direct cost and opportunity cost, the central government, Shaanxi, and the water-receiving regions' government have given the three cities a large number of ecological funds and other forms of compensation. In 2008, the three cities received the first transfer payments from the central government, with a total of 1.09 billion yuan (Li 2021). Since 2014, Tianjin, a water-receiving region, has paid counterpart cooperation funds to the three cities. All these funds are used to improve people's livelihoods and protect the ecological environment.

However, 24 of the 28 counties in the three cities are national poverty counties, and the economic level in the three cities is relatively low. There is a notable conflict between the strict water counterpart requirements and strong economic development demands in the three cities. Therefore, this study uses the three cities of Hanzhong, Ankang, and Shangluo as the study sites and focuses on the impact of water protection on their economic development.

\subsubsection{Data and Variables}

Under the guideline of the synthetic control method, after choosing the treatment cities, it is necessary to select the potential control cities. Subsequently, the preintervention period should be clarified, as well as the total duration of policy impact. Relevant predictive variables with a significant influence on economic growth should be identified. With the specific data, we can estimate the economic impact of the PWES policy during the postintervention period. 
Recall that Hanzhong, Ankang, and Shangluo are our study sites; that is, the treatment cities. Potential control cities should be similar to the treatment cities in terms of economic characteristics and not exposed to the PWES policy. The steps for choosing potential control cities are as follows: (1) initially select non-provincial-capital cities in other provinces (autonomous regions), as well as other cities in Shaanxi Province, which are similar to the treatment cities in terms of GDP or per capita GDP; (2) Remove cities exposed to the PWES policy but excluded from the treatment group (such as Shiyan in Hubei and Huangshan in Anhui); cities with severe missing data (such as Longnan in Gansu and Wuzhong in Ningxia); cities with shorter prefecture-level history (such as Bijie in Guizhou); and cities with large differences in geographical features and folk customs (such as Aba Tibetan Autonomous Prefecture in Sichuan). Finally, we identified 62 potential control cities.

We use annual city-level panel data for 2000-2017. We set 2008 as the timing of the PWES policy intervention. The synthetic control method requires a sufficiently large number of preintervention and postintervention periods. Considering the changes in the statistical caliber and the availability of data, we determine that the sample period begins in 2000 and ends in 2017. Since 2017, the PWES policy has been implemented nationwide, invalidating many cities as potential control units.

Concerning Abadie (2003) and Ando (2015), our outcome variable of interest is real per capita GDP, measured in yuan, with 2000 as the base year. Referring to Borrego-Marín (2015), and Zhang (2020), our predictors of economic growth are: (1) secondary and tertiary industries accounting for GDP to reflect local industrial structure; (2) gross industrial output above scale to indicate economic development achievements; (3) population density to reflect labor conditions; (4) ratio of fixed asset investment to GDP to characterize capital input; (5) education expenditure to reflect human capital level; and (6) road density to measure infrastructure status. In addition, some special predictors in specific years are added to improve the fitting accuracy, such as real per capita GDP values in 2000,2004, and 2006. We obtain these data from the "China City Statistical Yearbook", with some missing data supplemented by the statistical yearbooks and bulletins of national economic and social development in relevant provinces and cities.

\subsubsection{The Need for Synthetic Control Analysis}

It is important to note that the synthetic control mimics the pre-treatment cities much better than simpler types of controls. Figure 2 plots the trends in real per capita GDP of the three cities, the national average, and the average of the control cities. As can be seen, the real per capita GDP of the three cities is far lower than the national average. Similarly, the trend for the average of the control cities differs notably from that of the three cities. The indicators of each control city are also not well matched. None of them are appropriate controls. Therefore, we construct a suitable counterfactual using the synthetic control method to better fit economic characteristics.

\section{Result And Analysis}


Based on the synthetic control method, this study uses the R package Synth to estimate the impact. The research idea is as follows: We first discuss the match between each treated city and its synthetic counterpart in the pre-PWES period, and then analyze the policy effects of PWES based on the discrepancy between the actual value and the counterfactual outcome in the post-PWES period, and finally conduct placebo tests and robustness tests of the empirical results.

\subsection{The Pre-PWES Fit}

As explained above, we construct synthetic cities as the weighted combination of control cities that most closely resemble the three cities in terms of pre-PWES values of economic growth predictors. To evaluate the quality of the match between the three cities and the synthetic controls, Table 1 compares them by predictive variables in the pre-PWES period, as well as the average values of the 62 control cities. To reduce multicollinearity and heteroscedasticity, this study uses the logarithm of the absolute values (Grier and Maynard 2016).

Table 1 shows that there is not much difference in predictor values between each of the three cities and their synthetic controls, which indicates that the synthetic cities approximate the actual ones well. Although the population density of Shangluo and Hanzhong, and the sectoral ratio of Ankang are slightly different, they are all within a reasonable range of $10 \%$. In addition, Shangluo has the lowest MSPE, which is only 0.0002 , indicating that the fit is quite good, followed by Ankang, which has an MSPE of 0.0008 , and Hanzhong, which has an MSPE of 0.0037. In general, the synthetic method provides an excellent fit for economic growth determinants in the three cities prior to the implementation of PWES. The good fit of the three cities during the pre-PWES period provides a basis for the synthetic analysis of the post-PWES period. 
Table 1

The real value and the synthetic value of the predictive variables before intervention

\begin{tabular}{|c|c|c|c|c|c|c|c|}
\hline \multirow[t]{2}{*}{ Variables } & \multicolumn{2}{|l|}{ Shangluo } & \multicolumn{2}{|l|}{ Ankang } & \multicolumn{2}{|c|}{ Hanzhong } & \multirow{2}{*}{$\begin{array}{l}\text { Average } \\
\text { of } 62 \\
\text { control } \\
\text { cities }\end{array}$} \\
\hline & Real & Synthetic & Real & Synthetic & Real & Synthetic & \\
\hline \multicolumn{8}{|l|}{$\begin{array}{l}\text { Sectoral ratio } \\
\text { (percentage) }\end{array}$} \\
\hline Secondary & 33.506 & 32.075 & 27.874 & 30.833 & 38.124 & 37.615 & 42.094 \\
\hline Tertiary & 40.234 & 39.941 & 45.634 & 37.950 & 39.128 & 39.667 & 33.550 \\
\hline $\begin{array}{l}\text { Log (gross } \\
\text { industrial output } \\
\text { above scale) }\end{array}$ & 12.554 & 12.667 & 12.914 & 12.876 & 14.208 & 13.866 & 14.076 \\
\hline $\begin{array}{l}\text { Population } \\
\text { density }\end{array}$ & 125.034 & 161.436 & 125.902 & 125.844 & 138.104 & 176.882 & 360.829 \\
\hline Investment ratio & 60.254 & 61.343 & 56.762 & 56.608 & 37.580 & 40.072 & 48.399 \\
\hline $\begin{array}{l}\text { Log (education } \\
\text { expenditure) }\end{array}$ & 10.780 & 10.741 & 10.782 & 10.784 & 11.014 & 11.002 & 10.840 \\
\hline Road density & 37.416 & 36.365 & 41.778 & 39.843 & 35.082 & 34.987 & 56.000 \\
\hline \multicolumn{8}{|l|}{$\begin{array}{l}\text { Special } \\
\text { predictors }\end{array}$} \\
\hline $\begin{array}{l}\text { Log (Real per } \\
\text { capita GDP of } \\
2000)\end{array}$ & 8.280 & 8.276 & 8.490 & 8.486 & 8.670 & 8.688 & 8.856 \\
\hline $\begin{array}{l}\text { Log (Real per } \\
\text { capita GDP of } \\
2004)\end{array}$ & 8.080 & 8.087 & 8.190 & 8.199 & 8.430 & 8.460 & 8.616 \\
\hline $\begin{array}{l}\text { Log (Real per } \\
\text { capita GDP of } \\
2006)\end{array}$ & 7.780 & 7.776 & 7.900 & 7.898 & 8.260 & 8.204 & 8.251 \\
\hline $\begin{array}{l}\text { Sectoral ratio of } \\
\text { secondary (mean } \\
\text { interval from } \\
2000 \text { to } 2006 \text { ) }\end{array}$ & 32.328 & 31.379 & 26.048 & 28.793 & 38.600 & 36.966 & 39.797 \\
\hline $\begin{array}{l}\text { Population } \\
\text { density (2006) }\end{array}$ & 125.820 & 162.076 & 126.290 & 126.525 & 138.960 & 177.773 & 363.855 \\
\hline
\end{tabular}

NOTE: All predictive variables are averaged for the 2003-2007 period; population density is measured in persons per square kilometer; road density is measured in $100 \mathrm{~km} / \mathrm{km}^{2}$; investment ratio indicates the ratio of fixed assets to GDP. The MSPE time ranges from 2000 to 2007, and the synthetic value is the weighted average of 62 control cities according to the synthetic control method. 


\begin{tabular}{|c|c|c|c|c|c|c|c|}
\hline \multirow[t]{2}{*}{ Variables } & \multicolumn{2}{|c|}{ Shangluo } & \multicolumn{2}{|l|}{ Ankang } & \multicolumn{2}{|c|}{ Hanzhong } & \multirow{2}{*}{$\begin{array}{l}\text { Average } \\
\text { of } 62 \\
\text { control } \\
\text { cities }\end{array}$} \\
\hline & Real & Synthetic & Real & Synthetic & Real & Synthetic & \\
\hline $\begin{array}{l}\text { Road density } \\
\text { (mean interval } \\
\text { from } 2000 \text { to } \\
2006 \text { ) }\end{array}$ & 32.720 & 32.577 & 34.310 & 35.321 & 29.992 & 31.099 & 46.411 \\
\hline MSPE & \multicolumn{2}{|c|}{0.0002220579} & \multicolumn{2}{|c|}{0.0007824315} & \multicolumn{2}{|c|}{0.003673305} & - \\
\hline
\end{tabular}

\subsection{Economic Impact of PWES}

The left column of Figure 3 depicts the evolution path of the actual logarithm of the real per capita GDP of the three cities and their synthetic counterparts during 2000-2017, reflecting the impact of policy implementation on economic growth. As the figure shows, before the implementation of PWES, the actual curves of the three cities overlap or resemble the synthetic versions. After the implementation of PWES, the actual path is higher than the synthetic path, indicating that the actual value is greater than the synthetic value, that is, PWES has a positive impact on the per capita GDP and thus has a significant effect on the economic growth of the three cities.

The right column of Figure 3 plots the gap between the actual and synthetic values, while the gap after the policy implementation represents the net policy effect of PWES. As we can see, after the implementation, the gaps of the three cities are all above zero, which also suggests that the policy effect is positive. For Shangluo, since 2007, the policy effect has expanded rapidly, and after 2010, the growth rate slowed and reached a maximum value of 0.6 in 2017. For Ankang, since 2007, the policy effect has gradually increased. Although the gap narrowed in 2013, it increased rapidly and reached a maximum of approximately 0.3 in 2015, and then slightly decreased. For Hanzhong, since 2008, the effect has increased slowly. In 2012, the gap achieved a step-by-step leap and reached its maximum in 2017, approaching 0.4. In comparison, the policy effect of Shangluo was the most significant. The policy effects of Ankang and Hanzhong were also obvious, but it is not possible to measure which is better or worse because differences between the two cities have appeared before the intervention. Notice that the policy effects of Shangluo and Ankang have been positive since 2007. This may be due to the previous largescale water resource protection activities and the corresponding industrial structure adjustments.

\subsection{Validity Test}

To prove that the economic growth effect of the treatment cities is indeed derived from PWES rather than other factors, and that the policy effect is statistically significant, this study draws on the placebo test proposed by Abadie (2010). 


\subsubsection{Placebo Test for Single Control City}

The basic process of the placebo test is as follows: first, select a city in the control group that has not implemented PWES, assuming that the city is affected by PWES in 2008; then, construct a synthetic control counterpart of this city by using other control cities, and estimate the policy effect. If the effect value is much lower than the value of the three treatment cities, or opposite to that of the treatment cities, it means that the economic growth effect of the treatment cities is indeed derived from PWES, that is, the results of the empirical analysis are valid. Otherwise, the results are invalid.

Table 2 lists the synthetic control weights corresponding to each treatment city. We can see that for the synthetic Shangluo, Dingxi, Lijiang, and Pingliang have a relatively large weight, that is, $0.249,0.238$, $0.200,0.159$, respectively. For the synthetic Ankang, Baoshan, Wuwei, and Dingxi account for relatively large weight, that is, $0.415,0.145,0.142$, respectively. For the synthetic Hanzhong, Huaihua, Tianshui, and Qujing have larger weight, that is, $0.374,0.219,0.130$, respectively. Therefore, this study uses the eight cities with higher contributions as examples to illustrate the effect of the placebo cities. 
Table 2

City weights in the synthetic Shangluo, Ankang, Hanzhong

\begin{tabular}{|c|c|c|c|c|c|c|c|}
\hline Control & Shangluo & Ankang & Hanzhong & Control & Shangluo & Ankang & Hanzhong \\
\hline Weight & & & & Weight & & & \\
\hline Treatment & & & & Treatment & & & \\
\hline Tongchuan & 0 & 0.001 & 0 & Lincang & 0.004 & 0 & 0 \\
\hline Weinan & 0 & 0.002 & 0 & Guigang & 0 & 0.003 & 0 \\
\hline Yan'an & 0 & 0.002 & 0.048 & Baise & 0 & 0.002 & 0 \\
\hline Yulin & 0 & 0.075 & 0 & Meizhou & 0.075 & 0.001 & 0 \\
\hline Tianshui & 0.159 & 0.001 & 0.219 & Shanwei & 0 & 0.001 & 0 \\
\hline Wuwei & 0 & 0.145 & 0 & Yangjiang & 0 & 0.001 & 0 \\
\hline Zhangye & 0 & 0.004 & 0 & Qingyuan & 0 & 0.003 & 0 \\
\hline Pingliang & 0.200 & 0.002 & 0 & Chaozhou & 0 & 0 & 0 \\
\hline Qingyang & 0 & 0.001 & 0.005 & Yunfu & 0 & 0.001 & 0 \\
\hline Dingxi & 0.249 & 0.142 & 0.067 & Hebi & 0 & 0.001 & 0 \\
\hline Shizuishan & 0 & 0.001 & 0 & Luohe & 0 & 0 & 0 \\
\hline Zigong & 0 & 0.001 & 0 & Shangqiu & 0 & 0.001 & 0 \\
\hline Panzhihua & 0 & 0 & 0.032 & Xinyang & 0 & 0.002 & 0 \\
\hline Luzhou & 0 & 0.002 & 0 & Zhoukou & 0 & 0.001 & 0 \\
\hline Deyang & 0 & 0.001 & 0 & Zhumadian & 0 & 0.001 & 0 \\
\hline Mianyang & 0 & 0.002 & 0.007 & Bengbu & 0 & 0.001 & 0 \\
\hline Guangyuan & 0 & 0.003 & 0 & Huaibei & 0 & 0.001 & 0 \\
\hline Suining & 0 & 0.001 & 0 & Anqing & 0 & 0.002 & 0 \\
\hline Leshan & 0 & 0.001 & 0 & Fuyang & 0 & 0.002 & 0 \\
\hline Nanchong & 0 & 0.001 & 0 & Suzhou & 0 & 0.003 & 0 \\
\hline Meishan & 0 & 0.001 & 0 & Bozhou & 0 & 0.002 & 0 \\
\hline Yibin & 0 & 0.002 & 0 & Chizhou & 0 & 0.003 & 0 \\
\hline Guan'an & 0 & 0.002 & 0 & Jingdezhen & 0 & 0.001 & 0 \\
\hline
\end{tabular}

NOTE: The sum of the weights of the control cities corresponding to each treatment city is 1 , and the cities with larger weights are highlighted. 


\begin{tabular}{|c|c|c|c|c|c|c|c|}
\hline Control & Shangluo & Ankang & Hanzhong & Control & Shangluo & Ankang & Hanzhong \\
\hline Weight & & & & Weight & & & \\
\hline Treatment & & & & Treatment & & & \\
\hline Dazhou & 0 & 0.002 & 0 & Yingtan & 0 & 0.004 & 0 \\
\hline Ya'an & 0 & 0.001 & 0 & Ji'an & 0 & 0.002 & 0 \\
\hline Bazhong & 0 & 0.002 & 0 & Fuzhou & 0 & 0.003 & 0 \\
\hline Liupanshui & 0 & 0.003 & 0 & Shangrao & 0 & 0.002 & 0 \\
\hline Qujing & 0 & 0.002 & 0.130 & Suizhou & 0 & 0.002 & 0.029 \\
\hline Baoshan & 0.065 & 0.415 & 0 & Huaihua & 0 & 0.003 & 0.374 \\
\hline Lijiang & 0.238 & 0.050 & 0 & Jiamusi & 0 & 0.001 & 0 \\
\hline Pu'er & 0.009 & 0.080 & 0 & Heihe & 0 & 0.001 & 0.089 \\
\hline
\end{tabular}

Figure 4 presents the evolution path of the actual and synthetic real per capita GDP logarithms for the 8 cities. According to the characteristics of the curve, the policy effects of the placebo test are divided into three categories: (1) Before the policy implementation, the two lines almost overlap; after that, the real path is lower than the synthetic path, such as Tianshui, Wuwei, Pingliang, and Qujing, indicating that the city's policy effect is negative; (2) the actual path and the synthetic path almost coincide both before and after the implementation, such as Baoshan, Lijiang, and Huaihua, suggesting that the city's policy effect is almost zero; and (3) the gap between the true path and the synthetic path is very large during the whole period, such as that of Dingxi, implying that the city has a poor fit and the results are not for reference. The poor fit of Dingxi may be due to its low predictive value, which cannot be well approximated by other cities. From the above analysis, we know that the control cities with higher similarity to the treatment cities did not show positive policy effects. This indicates that the positive policy effect of the treatment cities is not due to accidental factors but is caused by the implementation of PWES.

\subsubsection{Permutation Tests for Multiple Control Cities}

Furthermore, this study uses permutation tests to assess whether the policy effect is statistically significant. The general idea is to select a series of control cities and conduct placebo tests one by one to obtain corresponding policy effects and then compare them with the treatment city. If these placebo effects are all smaller than that of the treatment city, the policy effect of the treatment city is demonstrated to be significant. It is difficult to interpret whether the gap of the post-PWES is due to calculating bias or policy intervention; therefore, we need to exclude cities with poor fit during the prePWES. This study excludes cities with a pre-PWES MSPE of more than twice the MSPE of the treatment city. Ultimately, 19 control cities are retained in Shangluo, 39 in Ankang, and 57 in Hanzhong. 
In Figure 5, each gray line represents the gap in per capita GDP between the control city and its synthetic version. Obviously, before the implementation of the policy, just like the control cities, Shangluo has a close-to-zero gap. But after the implementation, the estimated policy effect of Shangluo is particularly large. From the perspective of conventional statistical inference, the probability of such an unusual gap for Shangluo in our data is $1 / 20$, typically at a $5 \%$ significance level. For Ankang and Hanzhong, the path in the post-PWES period is also prominently higher than that of the control cities, which also means that it is a small probability event that the control group should obtain the same policy effect as the treatment city. To summarize, the implementation of PWES has markedly promoted the economic growth of the three treatment cities.

\subsection{Robustness Test}

In addition, to exclude the economic growth effects caused by other policies and related predictive variables, we use time-based placebo tests and add predictors to assess whether the policy effects are robust.

\subsubsection{Time-based Placebo Test}

We assume that the policy intervention time is advanced by three years to 2005 and rerun the synthetic model. Figure 6 shows the time-based placebo test. The results show that around 2005, the actual trajectory of the logarithm of the per capita GDP for each city is fairly close to its synthetic counterpart. It was not until 2007 or 2008 that there was a clear deviation between the two lines. This indicates that the hypothetical implementation of PWES in 2005 has no perceivable effect, which shows that the estimated results above are robust in terms of time, thus excluding the possibility of economic growth caused by other policies.

\subsubsection{Placebo Test of Additional Predictors}

To test whether the results above vary with the changing predictors, we conduct placebo tests by adding predictive variables of economic growth. Referring to Opatrny (2020) and Nannicini (2011), we use the urbanization rate and openness as additional predictors, as a high urbanization rate can provide a huge impetus, and openness can accelerate the reform process for economic growth. We use the proportion of the non-agricultural population in the total amount to measure the urbanization rate and the logarithm of total imports and exports to replace the openness.

Figure 7 illustrates the evolution path of economic growth by adding predictors of the urbanization rate and openness. Similarly, the fit of Shangluo is the best, followed by Ankang and Hanzhong; the actual and synthetic paths of Shangluo and Ankang are separated in 2007, and Hanzhong in 2008. This means that PWES has gradually played a role in promoting economic growth in the protected areas, but the timing that the effect appears in the three cities is different. In general, the test results show that the core conclusion that PWES promotes economic growth in the protected areas is robust.

\section{Discussion}


This section further analyzes the sources of PWES that promote economic growth and compares our study with other studies.

\subsection{Industrial Structure and Pillar Industries}

In 2008, the three industrial structures of Shangluo, Ankang and Hanzhong were 25.6:39.0:35.4, 27.3:32.5:40.2, and 24.9:38.6:36 respectively. According to Huang (2013), the three cities were all in the early stage of industrialization, which lagged behind the national average level of mid-industrialization. After the implementation of PWES, in order to promote economic growth constantly, the three cities comply with the economic laws, continue to develop the secondary industry, and greatly promote the circular economy and ecological economy on the premise of water protection.

Taking Ankang as an example, the secondary industry has developed rapidly since 2000. By 2018, it was $55.28 \%$ of the entire industry, $22.78 \%$ higher than that in 2008 . Based on selenium-rich resources, Ankang has cultivated distinctive products such as tea, konjac, and livestock pigs. The proportion of seleniumenriched industries increased from 16.5\% in 2010 to $41.2 \%$ in 2020, such that the selenium-enriched industry became the first pillar industry. Additionally, Ankang has developed agri-tourism and promoted the integrated development of primary, secondary, and tertiary industries (AnkangMPCPRO 2020). This shows that the green industry system based on "eco-economy" has become a strong support for Ankang economic growth, and economic development is not in conflict with ecological protection; they can advance coordinately, which is also in line with the goal of sustainable development.

\subsection{Comparison with Similar Cities}

There is a confusion that the rapid economic growth of the protected area may simply be caused by the development of secondary industry, rather than the ecological protection effect caused by PWES. To eliminate this possibility, we compare cities with the same level of industrialization and a similar trend in industrial structure.

Recall that Baoshan in Yunnan Province has the largest contribution to the synthetic Ankang. The three industrial structures of Baoshan in 2008 were 31.8:28.5:39.7, indicating that Baoshan was also in the early stage of industrialization. Secondary industries have been promoted for economic development. By 2018 , the secondary industry accounted for $38.1 \%$ and has become increasingly dominant. However, the ecological economy has not been prominent in the industrial system, and its role in promoting the economy is not obvious. This demonstrates the placebo test result of Baoshan above, that is, if PWES is applied to Baoshan, there is no economic growth. This also indicates that the economic growth of the protected area is partly caused by the eco-economic development triggered by PWES.

\subsection{Comparison with Other Studies}

The impacts of PWES are mostly concentrated in the household socioeconomic, cultural system, and ecological environment (Calvet-Mir et al. 2015; Liu and Kontoleon 2018; Torres 2016). Few studies have 
focused on the aggregate economic impacts of protected regions. This study is innovative as it evaluates the overall economic impact of the headwater area in the SNWD-MR.

Synthetic control methods are mostly used in the socioeconomic, environmental, and medical health fields (Degli Esposti et al. 2020; Ferraro and Hanauer 2014). In the economic field, research mostly involves the impact of specific policies or events such as economic liberalization (Billmeier and Nannicini 2013), trade openness (Nannicini and Billmeier 2011), and agricultural policy (Opatrny 2020), while in the environmental field, research has mainly focused on the impact of natural disasters, resource business, and the atmospheric environment(Cavallo et al. 2013; Pellegrini et al. 2021; Peng et al. 2020). Therefore, the application of this method in this study is leading in the comprehensive field of economy and ecology.

When verifying the evaluation results, we combine the studies of Abadie $(2010,2015)$, Grier (2016), and others, and conduct placebo tests, statistical significance tests, and robustness tests, making the verification process rigorous.

The disadvantage is that when evaluating the contribution to economic growth, this study only uses the predictors of the treatment cities during the preintervention period, but does not consider the postintervention period (Xu 2017). The study does not analyze deeply the reasons for the differences in policy effects among the three cities, which should be resolved and improved in follow-up studies.

\section{Conclusion}

The economic impact of PWES on the protected areas should be instructive only by using scientific methods to conduct specific analysis. In this study, we take the headwater area in SNWD-MR as an example to conduct an in-depth study of the economic impact. The appropriate counterfactual control region is constructed using the synthetic control method, and the real per capita GDP of the protected regions is compared with the counterfactual group. The results are as follows:

(1) The per capita GDP of treatment cities increased markedly relative to the synthetic regions, and the policy effect of PWES is positive; that is, the policy has promoted the economic development of the protected cities.

(2) The validity of the estimation is demonstrated by the placebo tests of single cities and the permutation tests of multiple cities; the robustness is proved by placebo tests of changing time and adding predictors.

(3) The economic growth is largely attributed to the development of the ecological-economic industrial system in protected areas.

The application of the synthetic control method to the field of PWES and the rigor of the verification process in this study can be used as a reference for related research. This economic development pattern can be used by other protected cities; that is, relying on natural resources, the protected city can take advantage of the ecological environment; ecologicalize the industry; and develop a green economy, 
circular economy, and ecological economy to protect the environment and realize the coordinated progress of economic development and environmental protection and achieve sustainable development.

\section{Declarations}

\section{Ethical Approval}

All work is compliance with Ethical Standards.

\section{Consent to Participate}

All authors give their permission.

\section{Consent to Publish}

All authors give their permission.

\section{Authors Contributions}

JM Zhang: Methodology, Data curation, Formal analysis, Writing - original draft; JW Zhu: Project administration, Supervision; Y Liu: Data curation, Investigation; N Lu: Writing - review; WX Fang: Data collection.

\section{Funding}

This study was funded by Project of National Natural Science Foundation of China (Grant number 71774132), Shaanxi Water Conservancy Science and Technology Project (Grant number2020SLKJ-22), Shaanxi Provincial Department of Education Key Scientific Research Project (Grant number 20JT053).

\section{Competing Interests}

The authors declare no competing interests.

\section{Availability of data and materials}

Data available after request from the authors

\section{References}


1. Abadie A, Gardeazabal J (2003). The economic costs of conflict: a case study of the Basque Country. Am Econ Rev 93:113-132.

2. Abadie A, Diamond A, Hainmueller J (2010). Synthetic control methods for comparative case studies: estimating the effect of California's tobacco control program. J Am Stat Assoc 105:493-505.

3. Abadie A, Diamond A, Hainmueller J (2011). Synth: an R package for synthetic control methods in comparative case studies. J Stat Softw 42:1-17.

4. Abadie A, Diamond A, Hainmueller J (2015). Comparative politics and the synthetic control method. Am J Pol Sci 59:495-510.

5. Akhbari M, Grigg NS (2013). A framework for an agent-based model to manage water resources conflicts. Water Resour Manag 27:4039-4052.

6. Alix-Garcia JM, Sims KRE, Orozco-Olvera VH, Costica LE, Fernández Medina JD, Romo Monroy S (2018). Payments for environmental services supported social capital while increasing land management. Proc Natl Acad Sci U S A 115:7016-7021.

7. Ando M (2015). Dreams of urbanization: quantitative case studies on the local impacts of nuclear power facilities using the synthetic control method. J Urban Econ 85:68-85.

8. Angrist JD, Pischke J-S (2017). Undergraduate econometrics instruction: through our classes, darkly. J Econ Perspect 31:125-144.

9. AnkangMPCPRO (2020).Ankang's four years of economic growth continued to lead the province. zys.ankang web. https://zys.ankang.gov.cn/Content-2046720.html. Accessed 16 March 2020.

10. Azevedo de Melo N, Minuzzi Delevati D, Ben da Costa A, Lobo EA (2021). The use of phytosociology to evaluate the efficiency of headwater preservation areas in the Andreas Stream Hydrographic Basin, RS, Brazil. Ecol Indic 129:107904.

11. Billmeier A, Nannicini T (2013). Assessing economic liberalization episodes: a synthetic control approach. Rev Econ Stat 95:983-1001.

12. Boelee E, Janse J, Le Gal A, Kok M, Alkemade R, Ligtvoet W (2017). Overcoming water challenges through nature-based solutions. Water Policy 19:820-836.

13. Borrego-Marín MM, Gutiérrez-Martín C, Berbel J (2015). Estimation of cost recovery ratio for water services based on the system of environmental-economic accounting for water. Water Resour Manag 30:767-783.

14. Calvet-Mir L, Corbera E, Martin A, Fisher J, Gross-Camp N (2015). Payments for ecosystem services in the tropics: a closer look at effectiveness and equity. Curr Opin Environ Sustain 14:150-162.

15. Cavallo E, Galiani S, Noy I, Pantano J (2013). Catastrophic Natural Disasters and Economic Growth. Rev Econ Stat 95:1549-1561.

16. de Groot RBA, Hermans LM (2009). Broadening the picture: negotiating payment schemes for waterrelated environmental services in the Netherlands. Ecol Econ 68:2760-2767.

17. Degli Esposti M, Spreckelsen T, Gasparrini A, Wiebe DJ, Bonander C, Yakubovich AR, et al. (2020). Can synthetic controls improve causal inference in interrupted time series evaluations of public health interventions? Int J Epidemiol 49:2010-2020.

Page 17/26 
18. Engel S, Pagiola S, Wunder S (2008). Designing payments for environmental services in theory and practice: an overview of the issues. Ecol Econ 65:663-674.

19. Ferraro PJ, Hanauer MM (2014). Advances in measuring the environmental and social impacts of environmental programs. Annu Rev Environ Resour 39:495-517.

20. Grier K, Maynard N (2016). The economic consequences of Hugo Chavez: a synthetic control analysis. J Econ Behav Organ 125:1-21.

21. Hegde R, Bull GQ (2011). Performance of an agro-forestry based payments-for-environmental-services project in Mozambique: a household level analysis. Ecol Econ 71:122-130.

22. Huang QH (2013). The process of industrialization in China: stage, characteristic and prospect. Econ Manag 27:5-11 (in Chinese).

23. Huber-Stearns HR, Goldstein JH, Cheng AS, Toombs TP (2015). Institutional analysis of payments for watershed services in the western United States. Ecosyst Serv 16:83-93.

24. Kaplowitz MD, Lupi F, Arreola $O$ (2012). Local markets for payments for environmental services: can small rural communities self-finance watershed protection? Water Resour Manag 26:3689-3704.

25. Li M, Liang D, Xia J, Song J, Cheng D, Wu J, et al. (2021). Evaluation of water conservation function of Danjiang River Basin in Qinling Mountains, China based on InVEST model. J Environ Manage 286:112212.

26. Li YF (2021). The ecological compensation problem and countermeasure research in the water source area of the South-North Water Transfer: from the perspective of Shaanxi province. J Xi 'an Univ Financ Econ 34:81-90 (in Chinese).

27. Liu Z, Kontoleon A (2018). Meta-analysis of livelihood impacts of payments for environmental services programmes in developing countries. Ecol Econ 149:48-61.

28. Locatelli B, Rojas V, Salinas Z (2008). Impacts of payments for environmental services on local development in northern Costa Rica: a fuzzy multi-criteria analysis. For Policy Econ 10:275-285.

29. MEA (2005). Ecosystems and human well-being: wetlands and water. Synthesis. Washington, DC:World Resources Institute.

30. Miranda M, Porras IT, Moreno ML (2003). The social impacts of the payments for environmental services (PES) scheme in Costa Rica: a quantitative field survey and analysis of the Virilla watershed. London:International Institute for Environment and Development.

31. Nannicini T, Billmeier A (2011). Economies in transition: how important is trade openness for growth? Oxf Bull Econ Stat 73:287-314.

32. NDRC, SNWDSCS, MWR, MEP, MOHURD (2017). The 13th five-year plan for water pollution prevention and control and soil and water conservation in the Danjiangkou Reservoir area and the upstream.China.

33. Opatrny M (2020). The impact of EU accession on farm production in the Czech Republic: a synthetic control method approach. Czech J Econ Financ 70:281-307.

34. Pacetti T, Castelli G, Bresci E, Caporali E (2020). Water values: participatory water ecosystem services assessment in the Arno River Basin, Italy. Water Resour Manag 34:4527-4544. 
35. Pellegrini L, Tasciotti L, Spartaco A (2021). A regional resource curse? A synthetic-control approach to oil extraction in Basilicata, Italy. Ecol Econ 185:107041.

36. Peng J, Xiao J, Zhang L, Wang T (2020). The impact of China's 'Atmosphere Ten Articles' policy on total factor productivity of energy exploitation: empirical evidence using synthetic control methods. Resour Policy 65:101544.

37. Piaggio M, Siikamäki J (2021). The value of forest water purification ecosystem services in Costa Rica. Sci Total Environ 789:147952.

38. Shang W, Gong Y, Wang Z, Stewardson MJ (2018). Eco-compensation in China: theory, practices and suggestions for the future. J Environ Manage 210:162-170.

39. Torres $S$ (2016). The effects on values, beliefs and norms of payments for environmental services: evidence from a PES program in Colombia. Dissertation, Michigan State University.

40. Van Hecken G, Bastiaensen J, Windey C (2015). Towards a power-sensitive and socially-informed analysis of payments for ecosystem services (PES): addressing the gaps in the current debate. Ecol Econ 120:117-125.

41. Wunder S, Albán M (2008). Decentralized payments for environmental services: the cases of pimampiro and PROFAFOR in Ecuador. Ecol Econ 65:685-698.

42. Xu Y (2017). Generalized synthetic control method: causal inference with interactive fixed effects models. Polit Anal 25:57-76.

43. Zhang H, Wu S, Yu Y, Lei L (2020). Effects of payments for watershed services policy on economic growth: a case study based on the synthetic control method. Environ Dev Sustain 23:2739-2761.

44. Zhao ZY, Zuo J, Zillante G (2017). Transformation of water resource management: a case study of the South-to-North Water Diversion project. J Clean Prod 163:136-145.

\section{Figures}




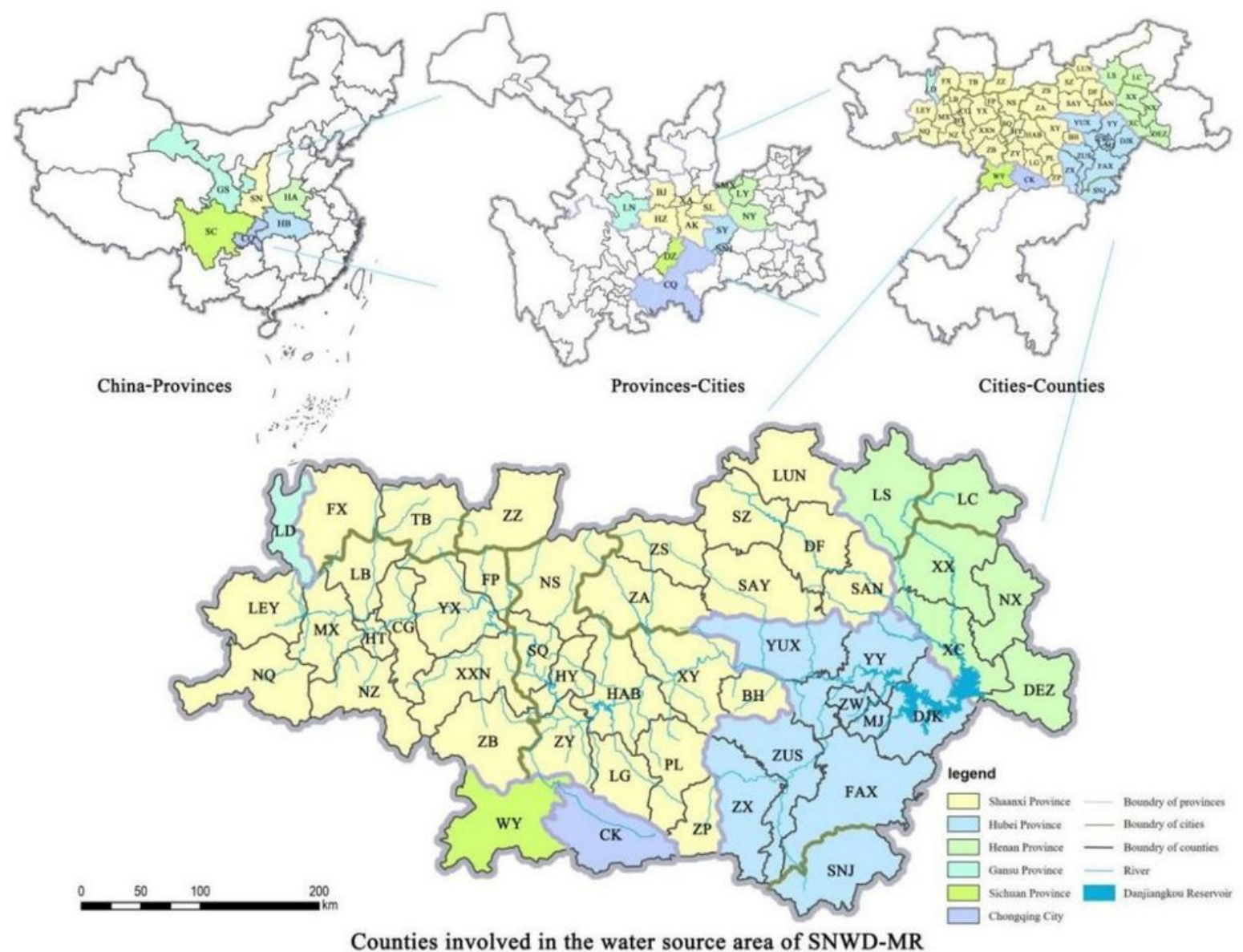

\section{Figure 1}

Distribution of the headwater area in SNWD-MR NOTES: The names of provinces, cities, and counties are all abbreviated. Among the cities involved, $\mathrm{HZ}$ is Hanzhong, AK is Ankang, SL is Shangluo, XA is Xi'an, BJ is Baoji, SY is Shiyan, SNJ is Shennongjia Forestry District, NY is Nanyang, LY is Luoyang, SMX is Sanmenxia, $L N$ is Longnan, and DZ is Dazhou. 


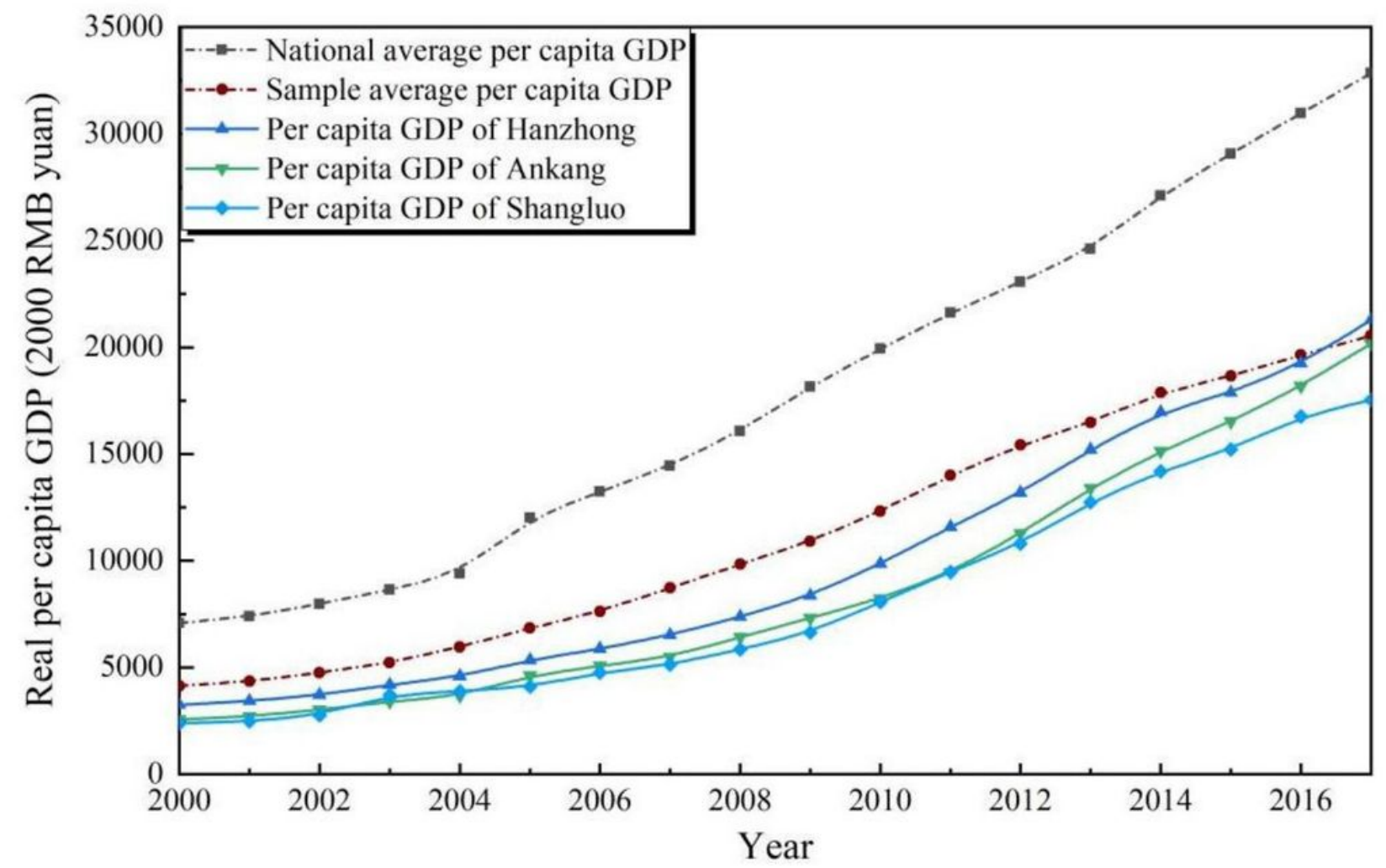

Figure 2

Trends in real per capita GDP for the three cities in Shaanxi, national average, and average for the control cities NOTES: The real per capita GDP is measured in yuan, with 2000 as the base year. 


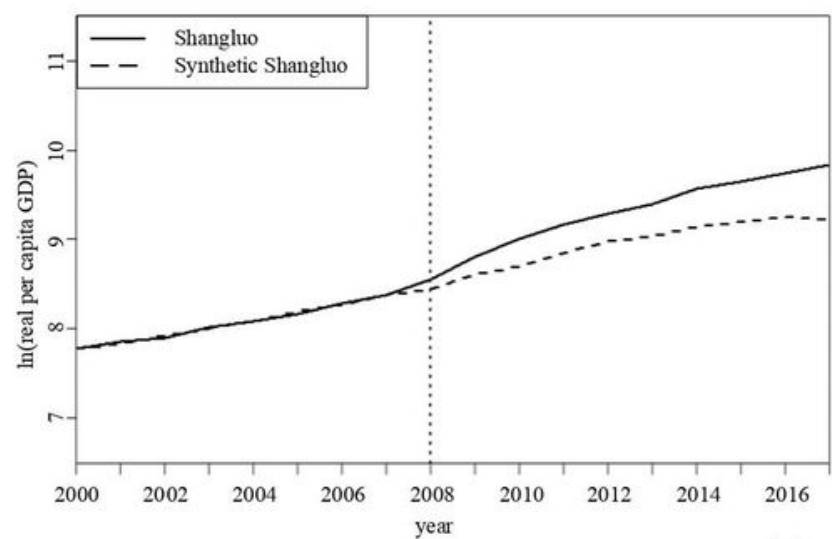

(a)

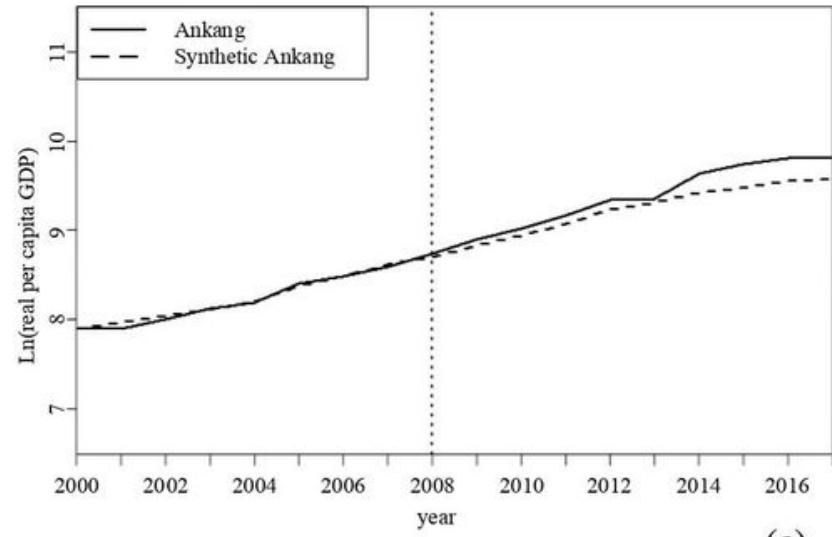

(c)

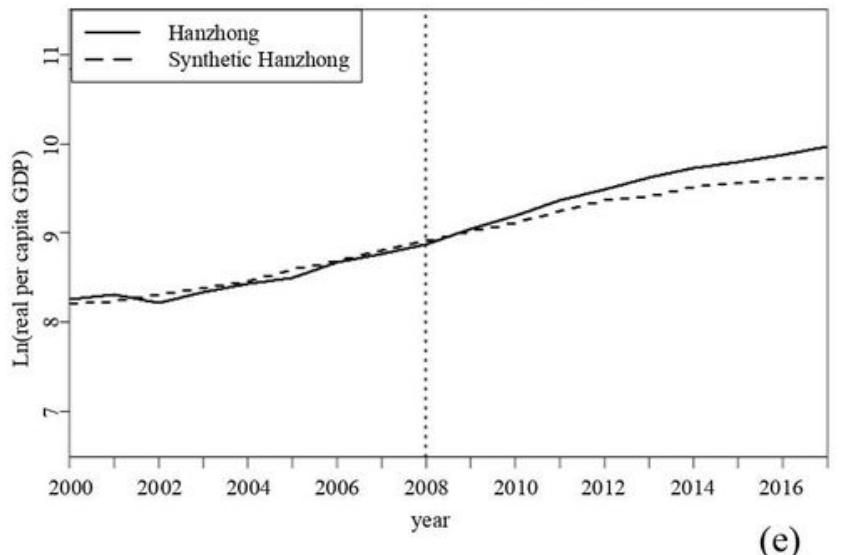

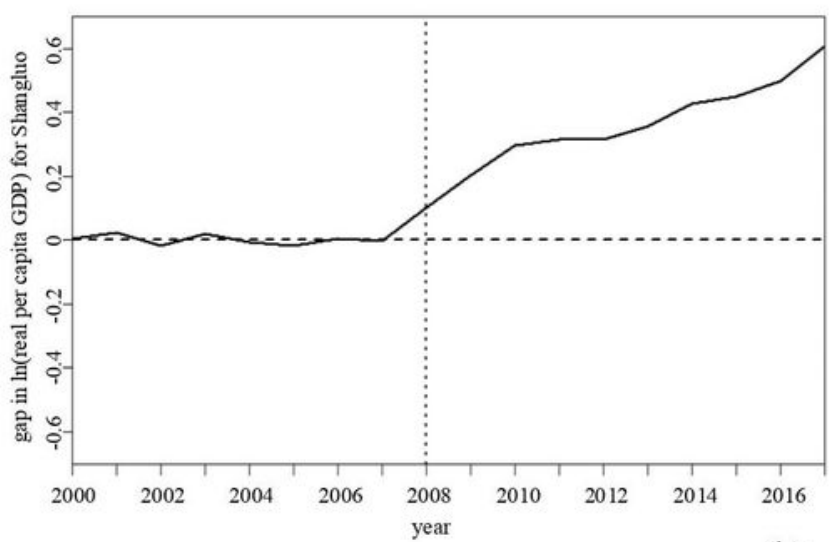

(b)

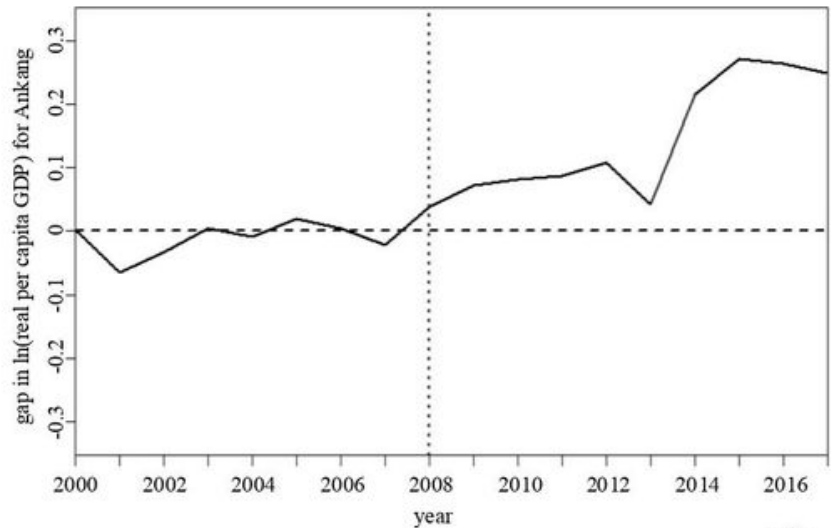

(d)

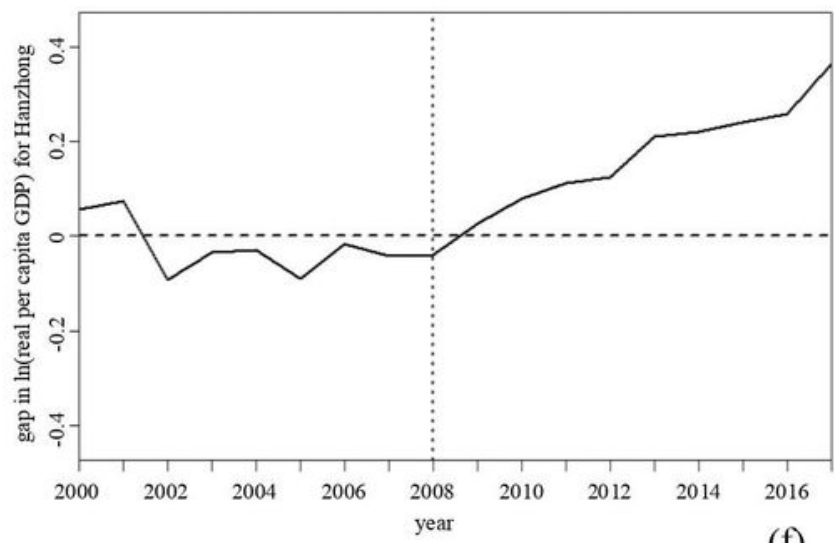

(f)

\section{Figure 3}

Economic growth effect of PWES NOTES: The left column depicts the evolution path of the real per capita GDP of the three cities and their synthetic counterparts; the right column plots the gap between the actual value and the synthetic value; the vertical line in each graph indicates the intervention year. 

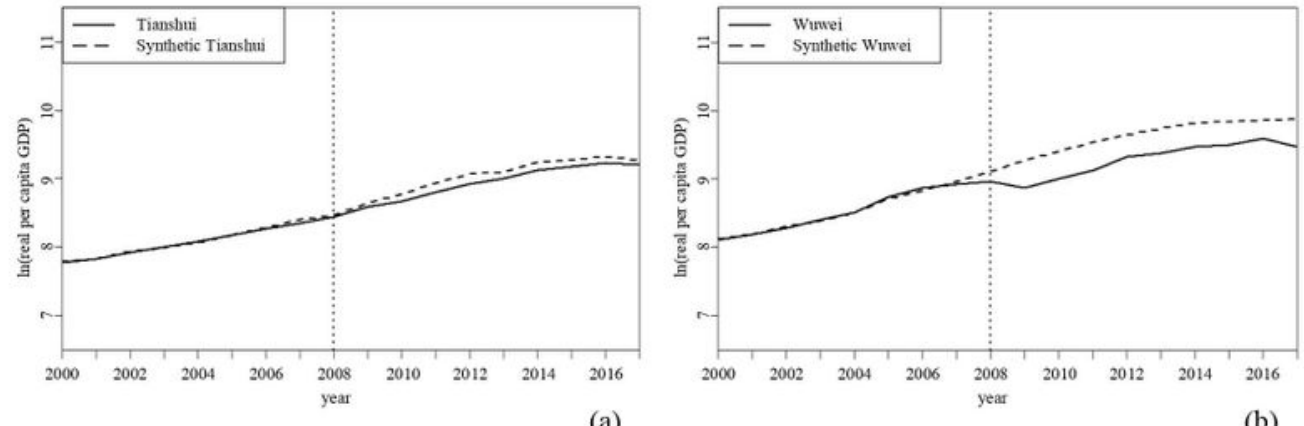

(a)

(b)
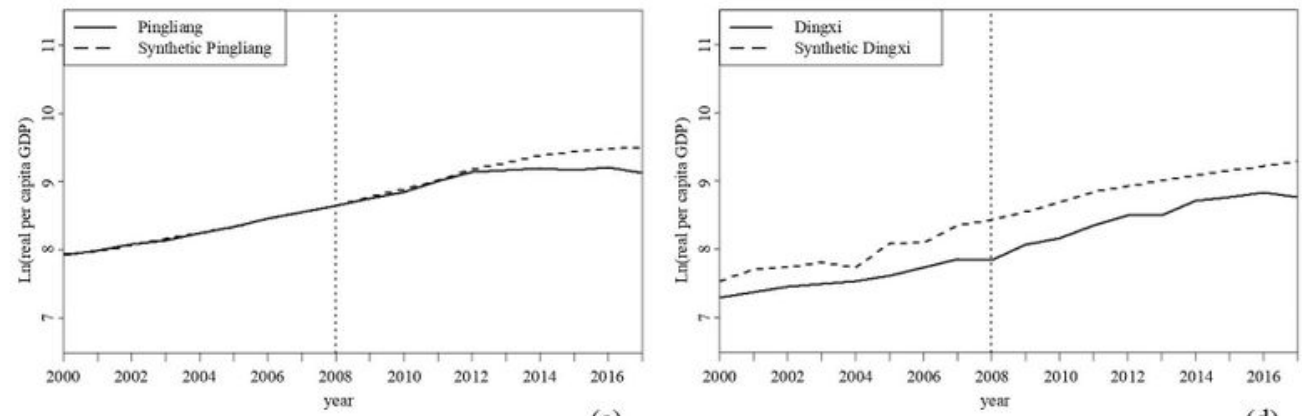

(c)

(d)
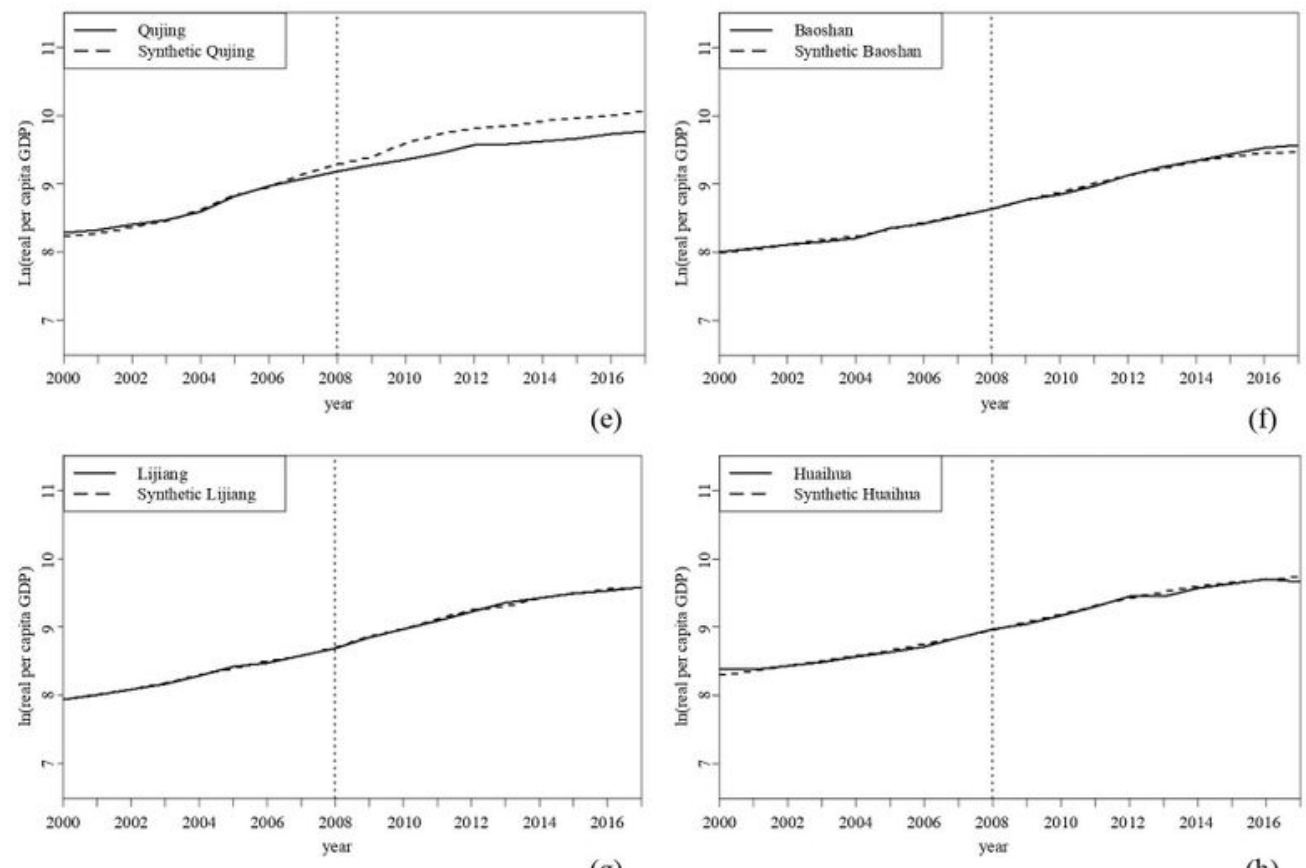

(g)

(h)

\section{Figure 4}

Placebo test for single control city 

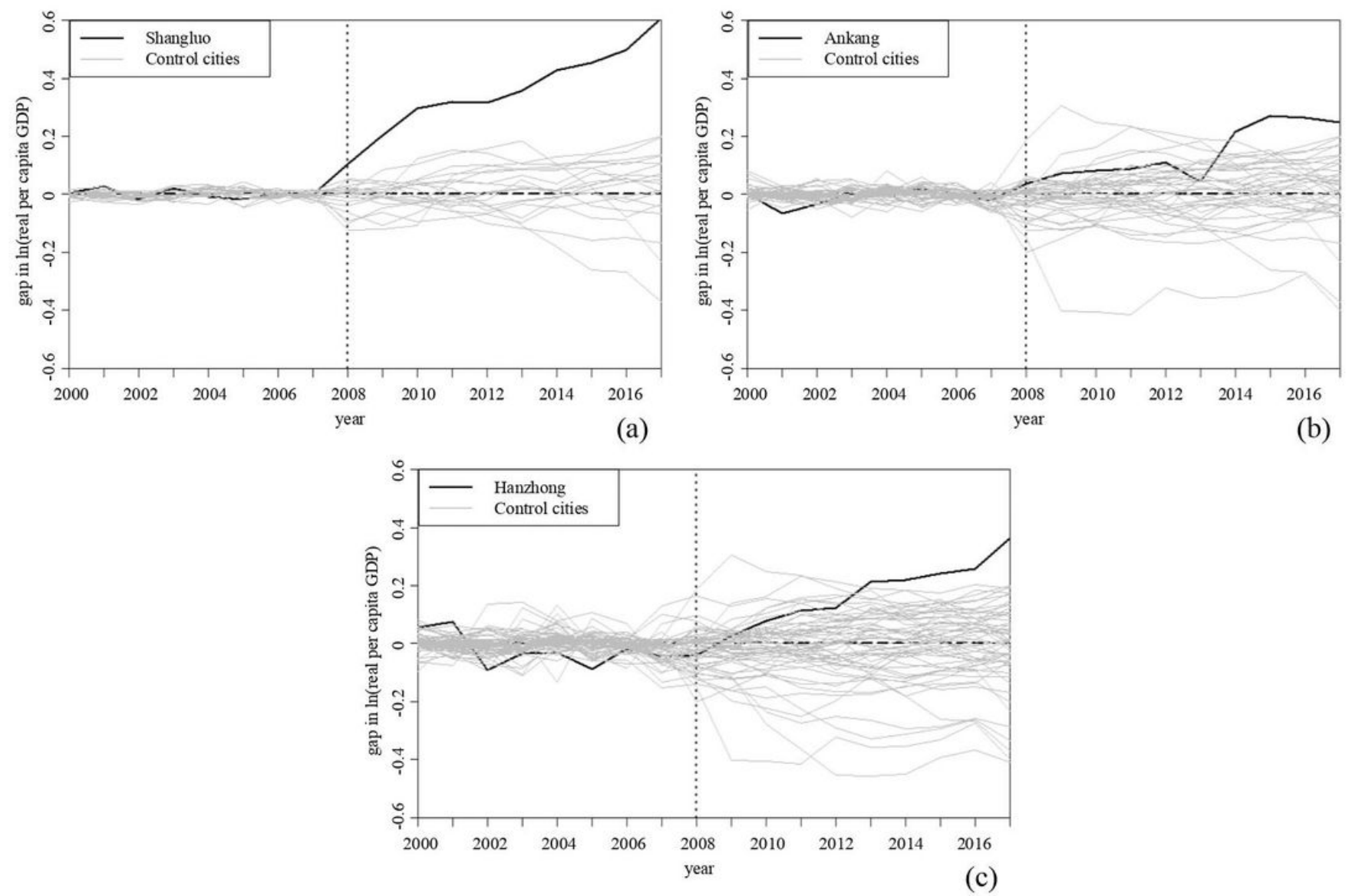

Figure 5

Permutation tests for multiple control cities NOTE: The black line denotes the gap estimated for the three treatment cities. The gray lines represent the gap associated with each placebo test. 

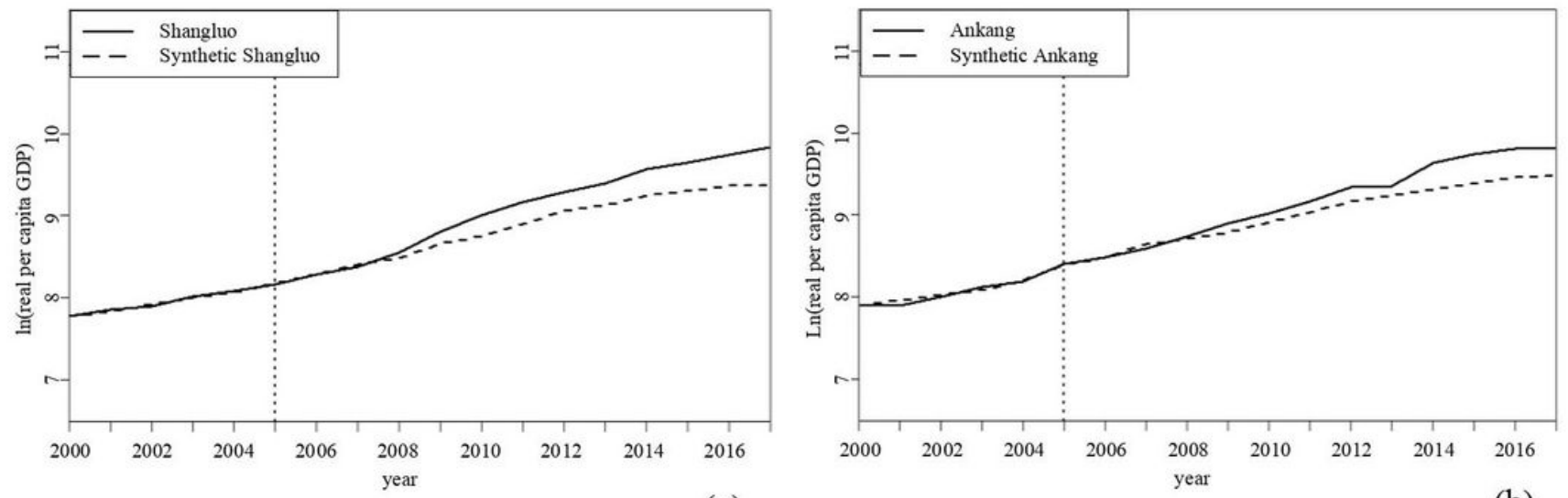

(a)

(b)

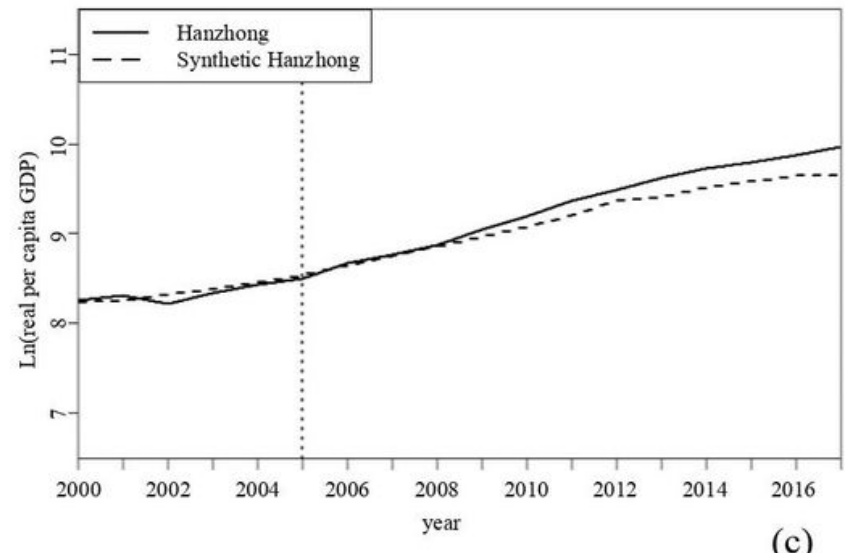

Figure 6

Robustness test: Time-based placebo test 

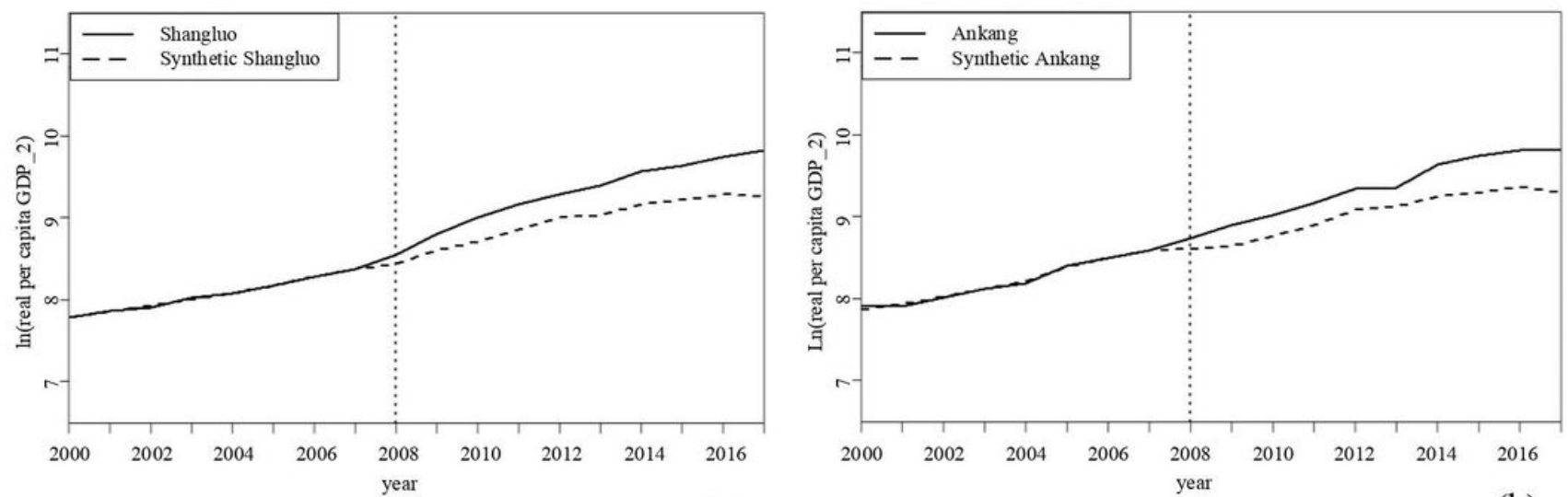

(a)

(b)

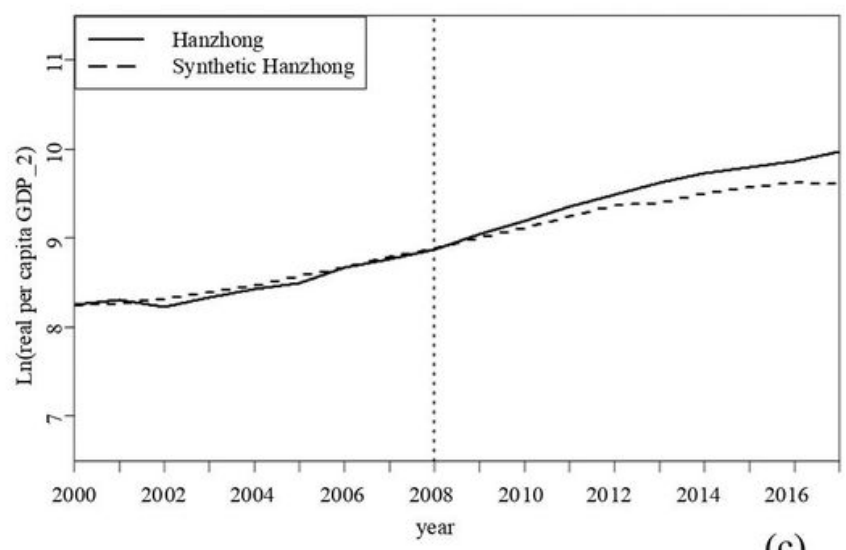

(c)

Figure 7

Robustness test: adding predictors 